\section{Pancreatic stent migration into the bile duct causing cholangitis}

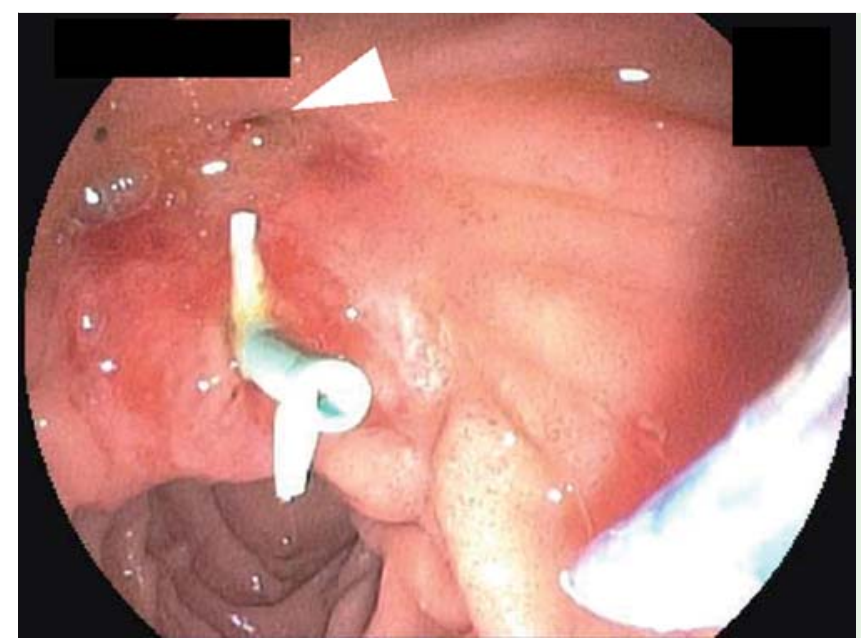

Fig. 1 Endoscopic view of the second portion of the duodenum in a 71-year-old woman with history of surgical sphincteroplasty for a benign ampullary stricture and recurrent episodes of acute pancreatitis. The pancreatic duct stent sits in the pancreatic duct; the arrowhead indicates the location of the biliary opening.

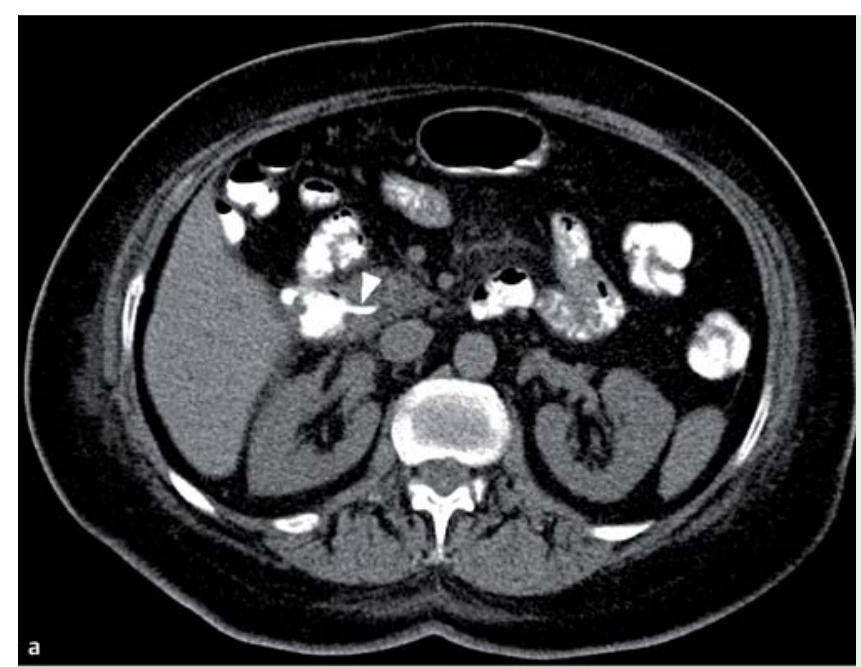

Fig. 2 a Computed tomography $(\mathrm{CT})$ scan of the abdomen on the day of the procedure shows the pancreatic duct stent at the head of the pancreas. b After 2 months, the stent was seen within the right intrahepatic duct.

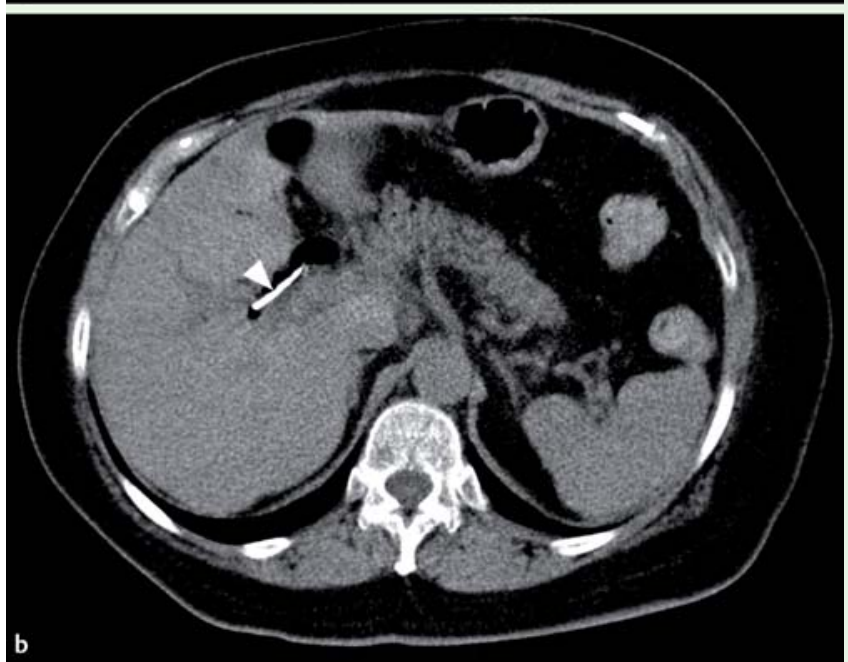

A 71-year-old woman with history of surgical sphincteroplasty for a benign ampullary stricture presented with recurrent episodes of acute pancreatitis. An endoscopic retrograde cholangiopancreatography (ERCP) showed the common bile duct outlet separated from the ampulla, and distal stenosis of the ventral pancreatic duct. A pancreatic sphincterotomy was carried out, followed by the placement of a straight plastic $5-\mathrm{Fr} \times 3 \mathrm{~cm}$ stent into the pancreatic duct ( $\bullet$ Fig. 1 ). Post procedure computed tomography, carried out for abdominal pain, showed the pancreatic stent lying within the head of the pancreas ( Fig.2a). An abdominal radiograph obtained 10 days later showed the stent in the area of the hepatic flexure, suggesting spontaneous distal migration ( $\bullet$ Fig.3). After 2 months, the patient presented with cholangitis. Abdominal CT revealed a bright linear object extending from the common hepatic duct to the right intrahepatic biliary tree ( $\bullet$ Fig. 2 b). An ERCP was done and the $5-\mathrm{Fr} \times 3 \mathrm{~cm}$ plastic pancreatic duct stent was removed from the right intrahepatic biliary tree using a biliary extraction balloon catheter. Distal spontaneous migration is common among $5-\mathrm{Fr} \times 3 \mathrm{~cm}$ pancreatic duct stents that do not have a flange on the pancreatic duct side; the migration rate is up to $96.7 \%$ by day 3 [1]. Proximal migration occurs in up to $5 \%$ of cases [2]. We present an unusual case of pancreatic stent migration where the stent migrated distally into the duodenum and then migrated into and far up the biliary tree, causing cholangitis. Surgical sphincteroplasty probably allowed entry of the straight stent into the biliary tree. We suggest the use of single-pigtail pancreatic duct stents in patients with altered ampullary anatomy to decrease the risk of such occurrences.

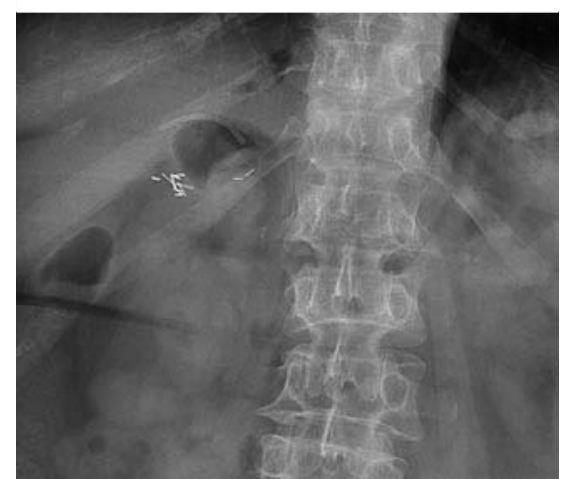

Fig. 3 X-ray of the abdomen 10 days after pancreatic stent placement. 
Endoscopy_UCTN_Code_CPL_1AK_2AD

Competing interests: None

\section{J. A. Zapatier, P. Jani, R. Pimentel, T. Erim}

Department of Gastroenterology and Hepatology, Cleveland Clinic Florida, Weston, Florida, United States of America

\section{References}

1 Kawaguchi $Y$, Ogawa M, Omata $F$ et al. Randomized controlled trial of pancreatic stenting to prevent pancreatitis after endoscopic retrograde cholangiopancreatography. World J Gastroenterol 2012; 18: 1635-1641

2 Price LH, Brandabur JJ, Kozarek RA et al. Good stents gone bad: endoscopic treatment of proximally migrated pancreatic duct stents. Gastrointest Endosc 2009; 70: 174-179

\section{Bibliography}

Dol http://dx.doi.org/

10.1055/s-0033-1344773

Endoscopy 2013; 45: E324-E325

(c) Georg Thieme Verlag KG

Stuttgart · New York

ISSN 0013-726X

\section{Corresponding author}

\section{T. Erim}

Department of Gastroenterology and Hepatology Cleveland Clinic Florida

2950 Cleveland Clinic Blvd.

Weston

Florida 33331

USA

Fax: +1-954-6595647

erimt@ccf.org 